\title{
プロファイルフィッティング法による炭素のX線回折データの解析
}

\author{
藤本宏之*
}

(平成14年9月4日受理, 平成14年10月1日採択)

\section{Analysis of X-ray Diffraction Pattern of Carbon by the Profile Fitting Method}

\author{
Hiroyuki Fujimoto*
}

The profile fitting method using the least square refinement was applied for the determination of the lattice constants and crystallite sizes of carbon. Firstly, the diffraction profiles of carbon and silicon as an internal standard were decomposed to the $K \alpha 1$ and $K \alpha 2$ profiles by Rachinger's method and then, the peak positions, heights and half widths of the two profiles were estimated. Using the obtained profile parameters as initial values, the least square refinements by Simplex method and Gauss-Newton method were carried out and both of the results were compared. The Gauss-Newton method showed the better convergence performance than that of Simplex method from the viewpoint of the convergence speed and the final convergence point.

KEYWORDS : Simplex method, Gauss-Newton method, Rachinger's method, Crystallite size

\section{1. 緒 言}

1963年に日本学術振興会炭素材料第117委員会によって, 「人造黒鉛の格子定数および結晶子サイズの測定方法」(便宜 上,「学振法'63」と呼ぶ) が制定されてから, およそ40年が経過 した1”。この間に, X線回折装置や制御あるいは解析のための コンピュータの技術が大きく進歩し, 学振法もその時代の技 術に即した方法へと改訂作業が進められている(「学振法'02」 と呼ぶ) 2)。筆者は, 改定案に準拠したCarbon Analyzer と呼ば れる解析プログラムを開発し, 現在市販されている。Carbon Analyzerでは, 炭素および内部標準であるシリコンのK $\alpha 1$ 線と K $\alpha 2$ 線の回折ピークを分離するためにPseudo-Voigt関数と呼 ばれるプロファイル関数を用いて実測回折プロファイルをフ イッティングする方法を採用している3!。その際, フィッティ ングの程度を表すR-因子を最小化させる方法としてSimplex 法を採用している。しかしながら,この方法は繰り返し計算 の回数が多く, 収束が遅いという欠点を有する。また最適解 を求める際の初期值をいかにして決定するかによって収束特 性が大きく左右される。

そこで, 本研究では収束特性を改善し, 解析精度を向上させ るために, Gauss-Newton法 (GN法)による解析法を検討し, Simplex法との収束特性の比較を行うことにした。また収束 特性に影響を与える初期值の決定方法としてRachingerのピ 一ク分離方法も併せて検討することにした。

\section{2. 解析条件の検討および実験}

\section{1 プロファイル関数と最小二乗計算方法}

炭素掞よびシリコンの回折線プロファイルを表現するため

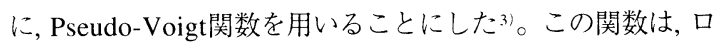
ーレンツ関数とガウス関数の混合関数であり,両者のそれぞれ の分率を $\eta,(1-\eta)$ で表すと, ピークトップTより低角側 $(2 \theta<$ $T)$, 高角側 $(2 \theta>T)$ では, プロファイル $\operatorname{Pr}(2 \theta)$ はそれぞれ

$$
\begin{aligned}
& P_{r}(2 \theta)=\eta \frac{2}{\pi \beta_{L}}\left[1+4\left(\frac{2 \theta-T}{\beta_{L}}\right)^{2}\right]^{-1} \\
& +(1-\eta) \frac{2}{\beta_{L}}\left(\frac{\ln 2}{\pi}\right)^{1 / 2} \exp \left[-4 \ln 2\left(\frac{2 \theta-T}{\beta_{L}}\right)^{2}\right] \\
& P_{r}(2 \theta)=\eta \frac{2}{\pi \beta_{R}}\left[1+4\left(\frac{2 \theta-T}{\beta_{R}}\right)^{2}\right]^{-1} \\
& +(1-\eta) \frac{2}{\beta_{R}}\left(\frac{\ln 2}{\pi}\right)^{1 / 2} \exp \left[-4 \ln 2\left(\frac{2 \theta-T}{\beta_{R}}\right)^{2}\right] \\
& \beta=\beta_{L} / 2+\beta_{R} / 2=\left(1+R_{L R}\right) \beta_{R} / 2, \quad R_{L R}=\beta_{L} / \beta_{R}
\end{aligned}
$$

* Corresponding Author, E-mail: gn6h-fjmt@asahi-net.or.jp 奈良県桜井市朝倉台東6-3-17

6-3-17, Asakuradai-higashi Sakurai Nara 633-0003, Japan 
ファイル全体の情報を反映したピークトップおよび半価幅を 直接決定することができ，これより格子定数および結晶子サ イズを求めることができる。プロファイルとしては炭素およ

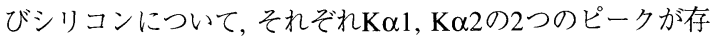
在するが, $\mathrm{K} \alpha 1, \mathrm{~K} \alpha 2$ のピークの強度比がおよそ2:1の相似型 ピーク関数であると仮定した。すなわち, 両者の半価幅 $\beta$, 口 ーレンツ分率 $\eta$ および非対称性パラメータ $R_{L R}$ は等しくなるよ うにし, $\mathrm{K} \alpha 1$ 線あるいは $\mathrm{K} \alpha 2$ 線のどちらか一方のパラメータ が変更されると連動して他方も変更されるようにプログラミ ングを行った。さらに, $K \alpha 1, K \alpha 2$ 回折線の位置はそれぞれの X線波長の違いによるものであるとの考え方から, それぞれの 回折角 $2 \theta_{1}, 2 \theta_{2}$ の間には

$$
\Delta \theta=2 \theta_{\alpha 1}-2 \theta_{\alpha 2}=2 \tan \theta_{\alpha 1} \cdot\left(\lambda_{\alpha 1}-\lambda_{\alpha 2}\right) / \lambda_{\alpha 1}
$$

の関係が成立するとして,フィッティングを行った。なお,フ イッティングの信頼性はR-因子

$$
R=\frac{\sum_{2 \theta}\left|I(2 \theta)-\sum P_{r}(2 \theta)\right|}{\sum_{2 \theta} I(2 \theta)} \times 100
$$

により評価した。ここで, $I(2 \theta)$ は実測プロファイルを表す。 Simplex法については, 市販されているCarbon Analyzer Version 2.12の解析手順をそのまま適用し, GN法による解析 は以下の手順に従った3)。

いま, 初期值のパラメータベクトル $p$ に対して, $\boldsymbol{e}$ だけ移動し たときに実測プロファイルとフィッティングプロファイルの 二乗残差の和

$$
\varepsilon=\sum_{i} v^{2}\left(2 \theta_{i}\right)=\sum_{2 \theta}\left(I\left(2 \theta_{i}\right)-P_{r}\left(2 \theta_{i}\right)\right)^{2}
$$

が最小になるとすると，

$$
\frac{\partial}{\partial p_{i}} \varepsilon(\boldsymbol{p}+\boldsymbol{e})=0
$$

となる。ここで, $\boldsymbol{\varepsilon}(\boldsymbol{p}+\boldsymbol{e})$ は, $\boldsymbol{p}$ に対して非線形であるので上式 をpのまわりでTaylor展開を行うと

$$
\begin{aligned}
\frac{\partial}{\partial p_{i}} \varepsilon(\boldsymbol{p}+\boldsymbol{e}) & =2 \sum_{j}\left(v\left(2 \theta_{j}\right) \frac{\partial v\left(2 \theta_{j}\right)}{\partial p_{i}}\right. \\
& \left.+e_{k} \frac{\partial v\left(2 \theta_{j}\right)}{\partial p_{k}} \frac{\partial v\left(2 \theta_{j}\right)}{\partial p_{i}}+e_{k} v\left(2 \theta_{j}\right) \frac{\partial^{2} v\left(2 \theta_{j}\right)}{\partial p_{i} \partial p_{k}}\right)
\end{aligned}
$$

となる。ここで

$$
\boldsymbol{A}_{j i}(2 \theta)=\frac{\partial v\left(2 \theta_{j}\right)}{\partial p_{i}}
$$

を要素とする行列 $\boldsymbol{A}$ を考えると最小点の近傍では第3項が無 視できるため

$$
\boldsymbol{A}^{\prime} \boldsymbol{A} \boldsymbol{e}=-\boldsymbol{A}^{\prime} s
$$

となる。これより $\boldsymbol{e}$ を求め $\boldsymbol{p}+\boldsymbol{e}$ を新しい初期值として繰り返 し計算を行い, 収束点を求めた。以上の計算を行うために, OS としてWindows2000を搭載したIntel Pentium III processor $(800 \mathrm{MHz})$ のパーソナルコンピュータを用いて, プログラミ ング言語にはVisualBasic6.0を使用した。

\section{2 最小二乗法による計算の際の初期値の決定}

一般に, 非線形最小二乗法においては, 初期值をどのように 決定するかということが重要である。収束特性が大きく左右 され, 発散する場合もあり得る。ここでは, 初期值を決定する ためにRachingerのピーク分離法を採用した。Rachingerの方 法は, 学振法'63においても採用されており,この方法によって 決定される初期值を用いて精密化を行うことは学振法の解析 精度を向上させる最も直接的な方法であると言える。この方 法によればCuK $\alpha 1$ 線およびK $\alpha 2$ 線の強度比 $I_{\alpha 2} / I_{\alpha 1}$ はおよそ 0.5 であり, K $\alpha 2$ 線プロファイルはK $\alpha 1$ 線のそれより式 (2)より見 積もられる $\Delta \theta$ だけ高角側にずれる。すなわち

$$
\begin{aligned}
& I_{\alpha 2}(2 \theta+\Delta \theta)=1 / 2 I_{\alpha 1}(2 \theta) \\
& I_{\text {Total }}(2 \theta+\Delta \theta)=I_{\alpha 1}(2 \theta+\Delta \theta)+I_{\alpha 2}(2 \theta+\Delta \theta)
\end{aligned}
$$

の関係が成立する。この方程式をそれぞれの測定点に対して 順次適用することで, $\mathrm{K} \alpha 1$ 線および $\mathrm{K} \alpha 2$ 線のプロファイルを 得ることができる。ここでは, $I_{\alpha 2} / I_{\alpha 1}$ 分離係数は 0.5 とした。 得られたそれぞれのプロファイルについて炭素およびシリコ ンの回折線のピークトップ位置, 強度, 半価幅および非対称性 を読み取り最小二乗計算のための初期值として採用した。ま た得られた值を用いて学振法'63に従った解析も同時に行い, Simplex 法およびGN法による解析結果との比較も行うことに した。

\section{3 解析試料}

解析データとしては岩下より提供された回折プロファイル デー夕を用いた2〉。この試料は, 東洋炭素(株)社製等方性黒鉛 (型番：IG-11)であり, 内部標準試料としてシリコンが混合さ れている。学振法に基づく各種強度補正を施した後, Rachingerの方法により $\mathrm{K} \alpha 1, \mathrm{~K} \alpha 2$ 線プロファイルに分離し Simplex法拉よびGN法を用いてプロファイルフィッティング を行い格子定数および結晶子サイズを算出した。

\section{3. 結果および考察}

\section{1 収束特性の比較}

Fig.1 Fig.4中の (A) に, それぞれ炭素の002, 004, 110, 112 および006回折線をRachingerの方法によってピーク分離した 結果を示す。Rachingerの方法は非常に簡便, かつ確実にピー ク分離できるメリットがあるが，一方ではデメリットとして 例えばFig.2 (A) とFig.3 (A) に見られるように2 $\theta=56.1^{\circ}$ 〜 $56.5^{\circ}$ と $2 \theta=76.5^{\circ} \sim 76.9^{\circ}$ の領域にK $\alpha 1$ 線プロファイルに非 常にブロードなゴーストピークが現れることである。このゴ 

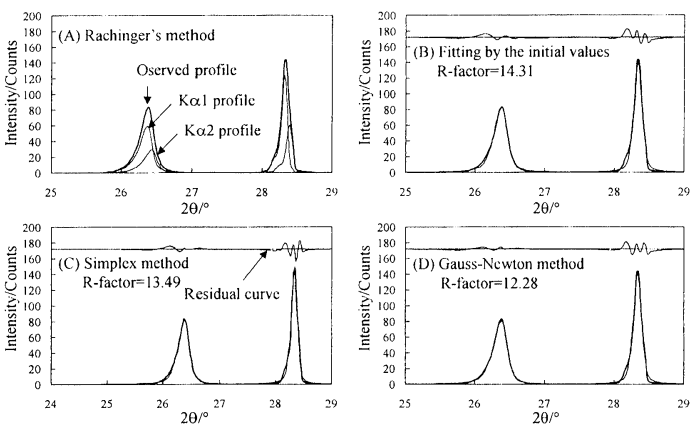

Fig.1 Profile fitting results for the 002 line of carbon and 111 line of silicon.
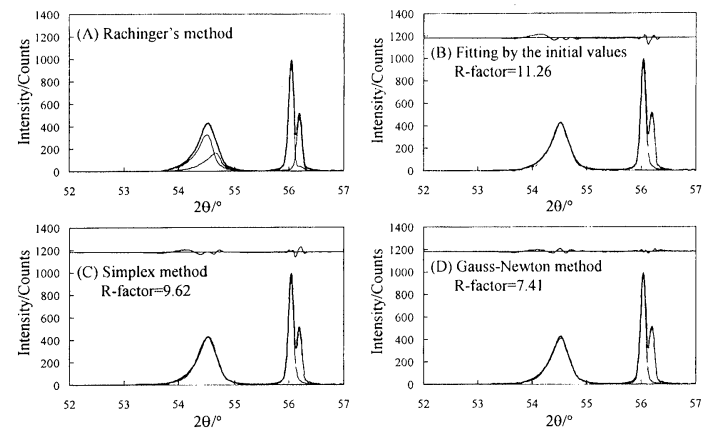

Fig.2 Profile fitting results for the 004 line of carbon and 311 line of silicon.
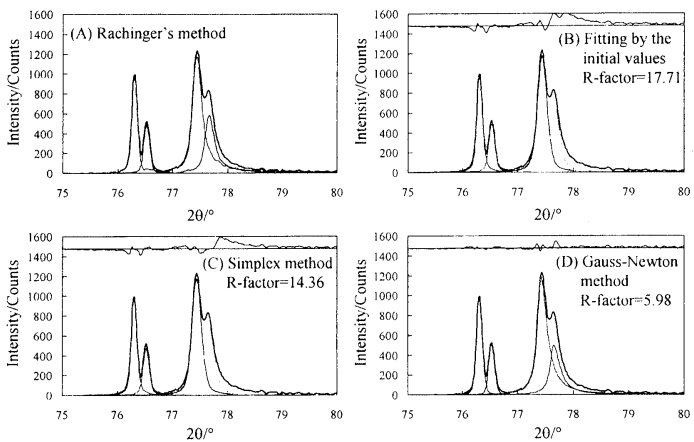

Fig.3 Profile fitting results for the 110 line of carbon and 331 line of silicon.
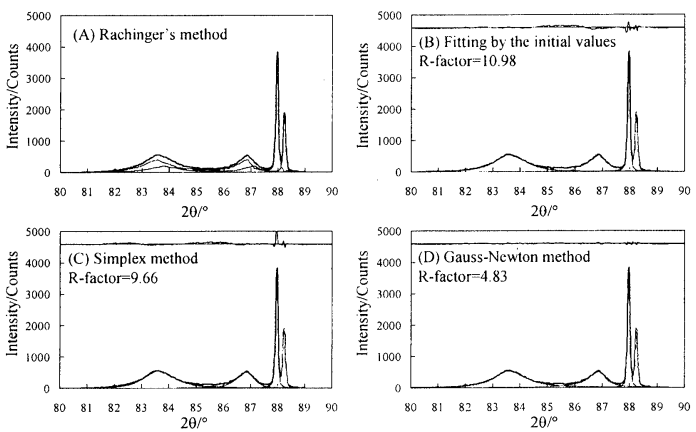

Fig.4 Profile fitting results for the 112 and 006 lines of carbon and 422 line of silicon.

Table 1 Convergence performance of Simplex method and Gauss-Newton method.

\begin{tabular}{|c|c|c|c|c|c|c|c|}
\hline \multirow[t]{2}{*}{$\begin{array}{l}\text { Deffraction } \\
\text { lines }\end{array}$} & \multicolumn{2}{|c|}{ R-factor/\% } & \multicolumn{2}{|c|}{$\begin{array}{c}\text { Repeat calculation } \\
\text { number/Cycle }\end{array}$} & \multicolumn{3}{|c|}{ Convergence time/sec } \\
\hline & $\begin{array}{l}\text { Simplex } \\
\text { method }\end{array}$ & $\begin{array}{c}\mathrm{GN} \\
\text { method }\end{array}$ & $\begin{array}{l}\text { Simplex } \\
\text { method }\end{array}$ & $\begin{array}{c}\mathrm{GN} \\
\text { method }\end{array}$ & $\begin{array}{l}\text { Simplex } \\
\text { method } / a\end{array}$ & $\begin{array}{c}\mathrm{GN} \\
\operatorname{method} / b\end{array}$ & $\begin{array}{c}a / b \\
\text { ratio }\end{array}$ \\
\hline 002 & 13.49 & 12.28 & 490 & 2 & 63.09 & 0.42 & 150.4 \\
\hline 004 & 9.62 & 7.41 & 490 & 5 & 90.38 & 0.93 & 96.9 \\
\hline 110 & 14.36 & 5.98 & 190 & 5 & 31.45 & 1.09 & 28.8 \\
\hline $112 \& 006$ & 9.66 & 4.83 & 390 & 2 & 171.21 & 1.21 & 141.1 \\
\hline
\end{tabular}

ーストピークの形状は $\mathrm{K} \alpha 1 / \mathrm{K} \alpha 2$ 分離係数に依存して変化す る。すなわち, 実測プロファイルの真のK $\alpha 2 / \mathrm{K} \alpha 1$ 分離係数が 実際の分離に用いた係数 0.5 との間にわずかな差異を生じる ために起こる現象である。また, Fig.1 (A) 中の $2 \theta=28^{\circ} \sim$ $29^{\circ}$ 付近のシリコンの 111 回折線の実測プロファイルの低角 側が歪を受けているが, このような歪形状がノイズも含めて 正確にK $\alpha 1, \mathrm{~K} \alpha 2$ 線に反映される。これに対して, プロファイ ルフィッティング法によるピーク分離法は, 計算が煩雑であ るが, 実測プロファイルのひずみやノイズを平滑化させプロ ファイル全体の情報を反映した格子定数と結晶子サイズを与 える。Rachingerの方法により分離したK $\alpha 1, \mathrm{~K} \alpha 2$ プロファイ ルより直接読み取ったそれぞれの回折線のピーク位置, 強度, 半価幅および非対称性をもとに, それらを初期値としてPseu-
do-Voigt関数プロファイルを生成させ実測プロファイルと重 ね合わせた結果をFig.1～Fig.4中の（B）に示す。ローレンツ 率のみプロファイルから直接読み取ることが不可能なため, 初期值として便宜上, 0.5 を採用した。収束計算前の段階での それぞれの回折プロファイルのR-因子は図中に示したとおり である。この初期值を用いてSimplex法およびGN法による繰 り返し収束計算を行った場合のフィッティング結果をFig.1

〜Fig.4中の (C) および (D) に示す。収束計算はR-因子の值 の小数第3位が変化しなくなった時点で終了とした。その時 点での值と繰り返し計算回数, 収束時間をTable 1に示す。い ずれの回折線においても, GN法のほうが, R-因子がより小さ くなっており, 解析精度の高いことがわかる。計算速度の点 においても, 演算速度を28～150倍に高速化することができ 

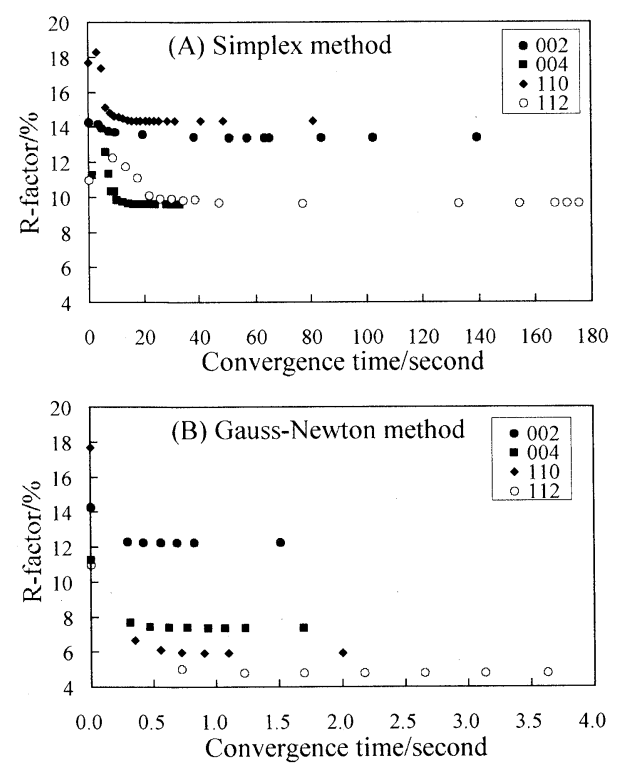

Fig.5 Convergence performance of Simplex method and Gauss-Newton method.

た。また, 収束計算に用いた初期値に関しては, 初期值より生 成したプロファイル関数は実測プロファイルのおよその形状 をほぼ再現しており, 収束計算においても発散することなく， 良好な収束結果を与えていることから実用上ほとんど問題な いと言える。Fig.5は, Simplex法およびGauss-Newton法を用 いて繰り返し収束計算を行った場合の演算時間に対するR-因 子の変化の様子である。いずれの回折線の解析結果において も, 前者よりも後者のR-因子が短時間でより小さな值に収束 し, 収束特性が極めて優れていることがわかる。

\section{2 学振法'63と学振法'02の解析結果の比較}

Rachingerの方法によりピーク分離を行った後, 学振法'63に 基づいて, それぞれの回折線のピーク位置, 強度, 半価幅を読み 取り, 格子定数および結晶子サイズを求めた結果をTable 2 中 の第2カラムに示す。またSimplex法, GN法により得た格子定 数および結晶子サイズを第3, 第4カラムに示す。

学振法'63では, 回折線のピーク位置はピーク強度の $2 / 3$ の位 置におけるピーク幅の中点をピーク位置 $T_{2 / 3}$ として計算して いる (2/3価幅法)。一方, 学振法63においては, プロファイル フィッティング法を採用しているため, ピークトップの位置 $T$ をそのまま採用している(ピークトップ法)。それゆえ, 回折 線プロファイルが完全対称なプロファイルである場合には, 両者のピーク位置は一致するが，そうでない場合には非対称 性の程度に依存して両者の值は異なることになる。両者の間 にはFig.6より幾何学的に次式の関係があることが導き出さ れる。

$$
T_{2 / 3}=\left\{T+\frac{1-R_{L R}}{2 x\left(1+R_{L R}\right)} \beta\right\} \times(1 \pm R / 100)
$$

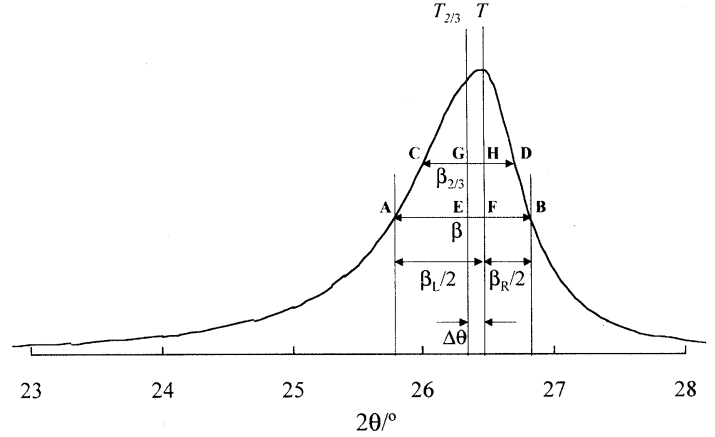

Fig.6 Relationship between the positions $\left(T\right.$ and $\left.T_{2 / 3}\right)$ estimated from the peak top of profile and the $2 / 3$ of height of peak top.

Table 2 Parameters obtained from Gakushin method'63 and Gakushin method'02.

\begin{tabular}{|c|c|c|c|}
\hline \multirow{2}{*}{ Parameters } & \multirow{2}{*}{$\begin{array}{l}\text { Gakushin } \\
\text { method'63 }\end{array}$} & \multicolumn{2}{|c|}{ Gakushin method'02 } \\
\hline & & $\begin{array}{l}\text { Simplex } \\
\text { method }\end{array}$ & $\begin{array}{c}\text { Gauss-Newton } \\
\text { method }\end{array}$ \\
\hline \multicolumn{4}{|l|}{ Peak position } \\
\hline $0021^{\circ}$ & $\begin{array}{c}26.3730 \\
\left(26.3700^{*}\right)\end{array}$ & 26.3863 & 26.3929 \\
\hline $004 /^{\circ}$ & $\begin{array}{c}54.5138 \\
\left(54.5081^{*}\right)\end{array}$ & 54.52694 & 54.5351 \\
\hline $0061^{\circ}$ & $\begin{array}{c}86.8405 \\
\left(86.8323^{*}\right)\end{array}$ & 86.8530 & 86.8959 \\
\hline $110 /^{\circ}$ & $\begin{array}{c}77.4394 \\
\left(77.4416^{*}\right)\end{array}$ & 77.4357 & 77.4207 \\
\hline $1121^{\circ}$ & $\begin{array}{c}83.6163 \\
(83.6174 *)\end{array}$ & 83.5541 & 83.5756 \\
\hline$d_{002} / \mathrm{nm}$ & $\begin{array}{c}0.33630 \\
\left(0.33637^{*}\right)\end{array}$ & 0.33626 & 0.33607 \\
\hline$d_{002(004)} / \mathrm{nm}$ & $\begin{array}{c}0.33620 \\
\left(0.33620^{*}\right)\end{array}$ & 0.33612 & 0.33609 \\
\hline$d_{002(006)} / \mathrm{nm}$ & $\begin{array}{c}0.33598 \\
(0.33632 *)\end{array}$ & 0.33600 & 0.33584 \\
\hline$a_{0} / \mathrm{nm}$ & $\begin{array}{l}0.24608 \\
(0.24607 *)\end{array}$ & 0.24609 & 0.24612 \\
\hline$d_{112} / \mathrm{nm}$ & $\begin{array}{c}0.11558 \\
(0.11557 *)\end{array}$ & 0.11566 & 0.11562 \\
\hline$L c_{(002)} / \mathrm{nm}$ & 64.04 & 59.63 & 60.28 \\
\hline$L c_{004} / \mathrm{nm}$ & 39.14 & 39.14 & 35.49 \\
\hline$L c_{006} / \mathrm{nm}$ & 19.34 & 19.20 & 19.98 \\
\hline$L a / \mathrm{nm}$ & 126.91 & 126.82 & 120.10 \\
\hline$L_{112} / \mathrm{nm}$ & 9.52 & 9.52 & 9.19 \\
\hline
\end{tabular}

* : The values in parentheses are estimated from the values obtained from Gakushin method'02

ここで, $x$ は半価幅と $2 / 3$ 価幅の比 $\beta / \beta_{2 / 3}$ であり, Gauss関数およ びLorentz関数で, それぞれ1.3075, 1.4142である。PseudoVoigt関数では, $\eta$ の関数として近似的に

$$
x=0.0331 \eta^{3}+0.0121 \eta^{2}+0.0615 \eta+1.3075 \text {. }
$$

で表される。したがってプロファイル関数の各パラメータを 用いて, $2 / 3$ 価幅法によるピーク位置を計算で求めることがで 
きる。Table 2中の第2カラム中の括弧内にGN法より得た各 プロファイルパラメータを用いて式 (11) に基づく $2 / 3$ 価幅法 によるピーク位置と面間隔値を推定した結果を示す。学振法 '63で求めたピーク位置と比較すると, その差は0.001 0.009 であり, 面間隔值換算でも最大 $0.0003 \mathrm{~nm}$ であった。フィッテ イング法のR-因子の值を考慮すれば,これらの差は䛊差範囲 内と考えられ, 学振法'63による格子定数の解析結果は学振法 '02の結果より推定できる。結晶子サイズについても両者の差 は0.6〜0.8nmであり, 誤差範囲内で一致した。

\section{4. 結 論}

\section{以上の検討の結果,}

（1）プロファイルフィッティングを行う際の初期值として Rachingerの方法により得られる值を用いることが有効 であること

（2）Simplex法からGN法へ切り替えることにより，フィッテ イングの収束時間を最大で約150分の1に短縮することが
でき，またR-因子をより小さな值に収束させ得ること

（3）プロファイルフィッティング法により得た各パラメータ を用いて従来法である学振法'63のデー夕を推定するこ とが可能であり,デー夕に互換性があること

が確認された。

\section{謝 辞}

解析用デー夕を提供していただいた独立行政法人産業技術 総合研究所の岩下哲雄氏に感謝いたします。

\section{文 献}

1) M. Inagaki, TANSO 1963 [No.36] 28-34 [in Japanese].

2）岩下哲雄, 藤本宏之, 白石稔, 稲坦道夫, 日本学術振興会炭 素材料第117委員会資料, 117-262-B4.

3）藤本宏之, 炭素構造解析ソフトウェア Carbon Analyzerマ ニュアル「標準シリコンによる補正解析法」に関する補 足解説ープログラムで採用した数式についてー (2002) pp.4-5, 株菱化システム。 